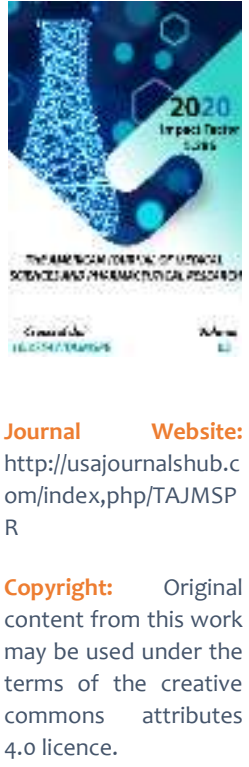

\section{Pharmacological Activity Of The Possessing New Atypical Neuroleptics 1-Phenyltetrahydroisoquinoline Structure}

\author{
Zafar Isomiddinovich Sanoev \\ Candidate Of Medical Sciences, Senior Scientific Researcher Of Department Of Pharmacology \\ And Toxicology Of Institute Of Chemistry Of Plant Substances, Academy Of Sciences Of \\ Republic Of Uzbekistan,Tashkent, Uzbekistan \\ Yuriy Rahmanovich Mirzaev \\ Candidate Of Medical Sciences, Senior Scientific Researcher Of Department Of Pharmacology \\ And Toxicology Of Institute Of Chemistry Of Plant Substances, Academy Of Sciences of \\ Republic Of Uzbekistan, Tashkent, Uzbekistan
}

\title{
ABSTRACT
}

The first synthesized derivative of (3द,4 $\$$-methylenedioxyphenyl) -6,7-methylenedioxy-1,2,3,4tetrahydroquinoline, conventionally designated F-29, showed neuroleptic properties - they have hypothermic, cataleptogenic, less pronounced suppression of motor activity, lack of central $\alpha$ adreno- and $\mathrm{M}$-anticholinergic action and less toxic in severity comparable to the activity of a more close analogue of the neuroleptic haloperidol, which has motor and autonomic disorders [1], which F29 lacks.

\section{KEYWORDS}

Neuroleptic activity, catalepsy, haloperidol, (3c,4c-methylenedioxyphenyl) -6,7-methylenedioxy1,2,3,4-tetrahydroquinoline.

\section{INTRODUCTION}

Neuroleptic (antipsychotic) drugs are widely used in the treatment of schizophrenia, manicdepressive psychoses, borderline states, etc. The number of patients reaches up to $1 \%$ of the population and is estimated at hundreds of thousands of patients, and in most cases the disease has a chronic course, and patients require constant supportive treatment. Neuroleptic drugs, despite the great need, are not produced in Uzbekistan. Therefore, the development of new neuroleptics from 
available raw materials with a new chemical structure, which will determine both a new mechanism of action and new therapeutic possibilities, is urgent. Among the 5 known groups of psychotropic drugs, neuroleptics take the 1st place in demand. Typical antipsychotics created in the middle of the last century - chlorpromazine, triftazine, haloperidol and others are indispensable in the treatment of the most severe mental disorders, but at the same time, they are not always effective, have side effects in the form of extrapyramidal movement disorders, parkinsonism, memory and mood disorders, lowering blood pressure, deterioration of vision, dyspepsia, etc., (M.D. Mashkovsky, 2017) [1]; B. Berman, 2011) [2] and poorly tolerated in old age (P. Gareri et al., 2014) [3]. In view of this, there was a need to create lighter antipsychotics, called "atypical antipsychotics".

\section{MATERIALS AND METHODS OF RESEARCH}

In the first synthesis of F-29, described in detail in the article by the authors [4], the starting compound was piperanal (1), which in 2 stages gave the target intermediate product homopiperanylamine (2).

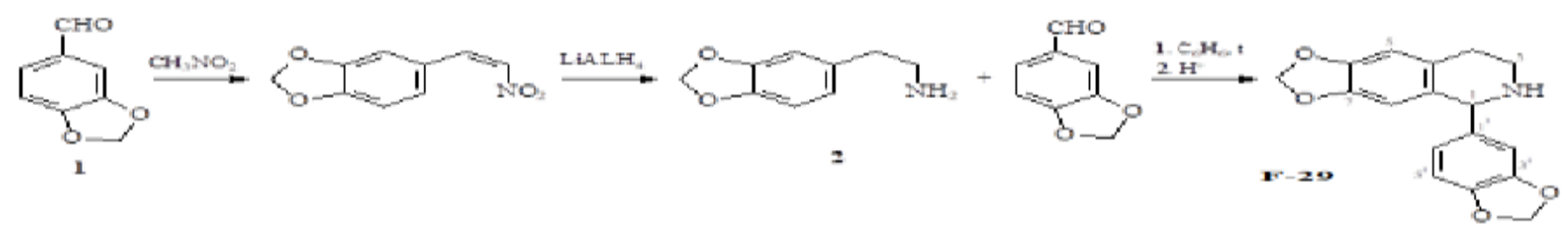

Fig. 1. Stages of synthesis of F-29, 1- (3ל,4ל-methylenedioxyphenyl) -6,7-methylenedioxy-1,2,3,4tetrahydroisoquinoline

All experiments were performed on white mice of both sexes weighing 18-20 g for 610 animals per group. Comparative studies of the effect of substances on locomotor activity (hereinafter LA) have been studied by the Lapin method [5], study of the cataleptogenic action [7] of F-29, haloperidol and risperidone, effect on etaminal sleep duration, effect on body temperature, influence on the locomotor action of phenamine.

\section{RESULTS AND DISCUSSION}

\section{General effect and toxicity of F-29 on} white mice when administered orally.

When studying the general effect and toxicity of F-29, it was noted that no noticeable external stable changes in the behavior of white mice were noted from doses of 3-10 mg / kg. From a dose of $20-50 \mathrm{mg} / \mathrm{kg}$, a general depression of the mice was noted, but if the mice were disturbed, then they showed adequate behavior. At doses of more than 100 $\mathrm{mg} / \mathrm{kg}$ and higher, mice exhibited more pronounced general depression, a sluggish response to pain and sound stimulation. The 
death of mice began at a dose exceeding 300 $\mathrm{mg} / \mathrm{kg}$, and the LD50 of F-29 when administered orally was $445(368 \div 538) \mathrm{mg} /$ $\mathrm{kg}$. The death of the mice occurred $60-340$ min after injection against the background of muscle weakness, prostration, and respiratory depression.

The LD50 of haloperidol when administered orally was also determined, which was 105 (83-133) $\mathrm{mg} / \mathrm{kg}$, that is, haloperidol is 4.2 times more toxic than F-29.

\section{Influence of F-29 and haloperidol on the motor activity of white mice after a single injection}

Experiments on white mice were carried out according to the Lapin method [5], where locomotor activity (hereinafter LA) was assessed by the number of times the mice crossed the floor lines under a glass cover in 1 $\min$.

F-29 was used in a wide range of doses from 0.1 to $100 \mathrm{mg} / \mathrm{kg}$ orally. As seen from fig. 2, LA in all groups of mice against the background of the drug decreased during the experiment and to a much greater extent than in control animals (from 4 to 20 times), sometimes until the complete disappearance of LA from a dose of $100 \mathrm{mg} / \mathrm{kg}$. Based on the results of the experiment, it can be concluded that the specific inhibitory effect of F-29 on LA, which is clearly noticeable even at a dose of $0.1 \mathrm{mg} /$ $\mathrm{kg}$ inside.

In comparative experiments with haloperidol, doses of 0.1 were used; 1.0 and $10 \mathrm{mg} / \mathrm{kg}$ orally. In fig. 3 shows the results of the experiment.
When comparing Fig. 2 and fig. 3 that the depressing effect of haloperidol on LA is much more pronounced than that of F-29. In particular, even at a dose of $100 \mathrm{mg} / \mathrm{kg}, \mathrm{F}-29$ does not cause such a pronounced inhibition of LA as haloperidol at a dose of $10 \mathrm{mg} / \mathrm{kg}$. Thus, the peak of action from F-29 came after 2 hours, and after 3 hours, LA began to recover, while for haloperidol (10 $\mathrm{mg} / \mathrm{kg}$ orally), the peak of action occurred after 3 hours, and there were no signs of LA recovery even after 6 hours, which indicates a significantly greater inhibition of the spontaneous motor activity of haloperidol in comparison with F-29. 


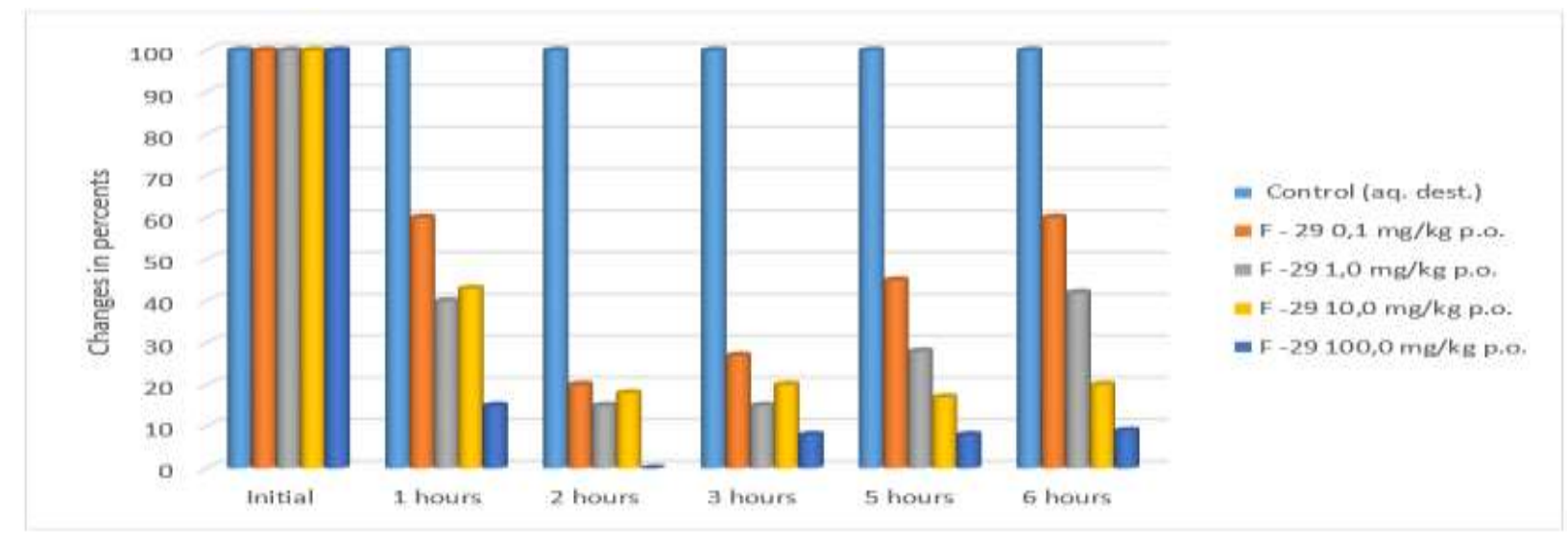

2. Influence of F-29 on the motor activity of white mice

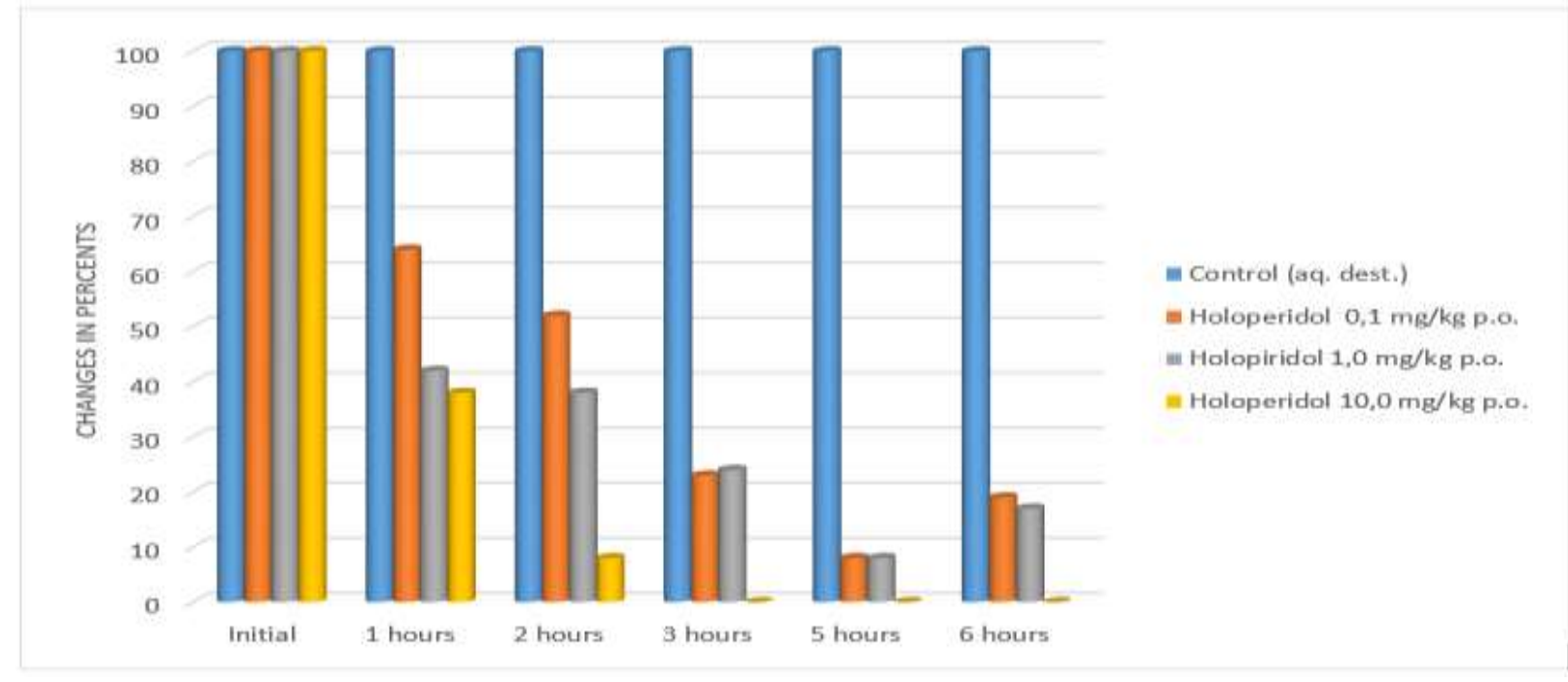

Fig. 3. Effect of haloperidol on the DA of white mice.

3. Study of the cataleptogenic action of F29 , haloperidol and risperidone.

After revealing the specific inhibitory effect of F-29 on LA, its cataleptogenic activity was tested in comparison with other classical antipsychotics haloperidol and risperidone. The severity of catalepsy was assessed by the duration of the preservation of the "lecturer's posture" in seconds and its duration of action in minutes. The results of the experiment are shown in fig. 4, from which it can be seen that the maximum of catalepsy in F-29 $(0.5 \mathrm{mg} / \mathrm{kg}$ s.c.), haloperidol ( $0.3 \mathrm{mg} / \mathrm{kg}$ s.c.) and risperidone ( $0.3 \mathrm{mg} / \mathrm{kg}$ s.c.) comes in 2-4 hours and after 5 hours there is a weakening of catalepsy 


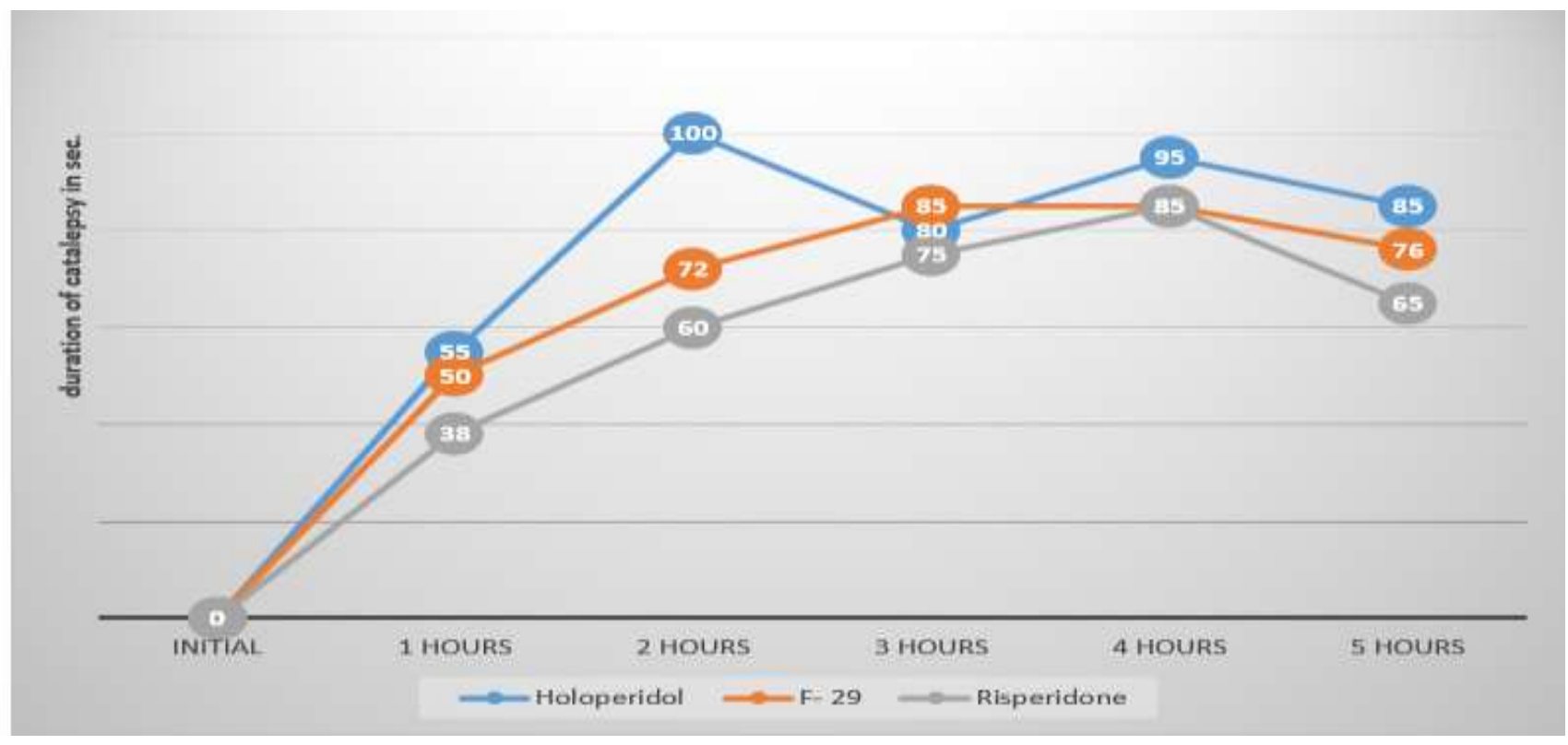

Fig. 4. Influence of F-29, haloperidol and risperidone on the severity catalepsy in experiments on mice

\section{Influence of F-29 and haloperidol on the duration of sleep from etaminal.}

Prolongation of the hypnotic effect of sodium ethaminal by neuroleptics is their specific action. F-29 was used in doses of 0.1; 1.0; 10.0 and 100, and haloperidol 0.1; 1.0 and $10.0 \mathrm{mg} / \mathrm{kg}$ orally.

4.1. In experiments with $\mathrm{F}-29$, the drug was administered orally 1 hour before etaminal at a dose of 40 $\mathrm{mg} / \mathrm{kg}$ ip. F-29 in all doses prolonged the hypnotic effect from 2.5 to 5 times, and large doses of F-29 caused a more pronounced lengthening of sleep, but not proportional to the dose.

4.2. In experiments with haloperidol, doses ranging from 0.1 to $10 \mathrm{mg} / \mathrm{kg}$ were used. The results from doses of 0.1 and 1.0 were approximately the same, but from a dose of $10 \mathrm{mg} / \mathrm{kg}$ haloperidol, an exorbitant lengthening of the hypnotic effect was observed, up to 6 times.

\section{Effect of F-29 and haloperidol on body temperature.}

All antipsychotics tend to lower body temperature. Experiments were carried out on rats to study the hypothermic action of F-29 and haloperidol in experiments on rats. Body temperature was measured using an electronic thermometer when the temperature sensor was immersed in the anus to a depth of $2-2.5 \mathrm{~cm}$.

Antipsychotics were administered orally in different doses: $0.1 ; 1.0$ and $10.0 \mathrm{mg} / \mathrm{kg}$. As shown in fig. 5, F-29 and haloperidol dose-dependently caused a decrease in body temperature, which confirms the belonging of compound F-29 to antipsychotics in this test. The hypothermic action of F-29 and haloperidol is shown in fig. 5 . 


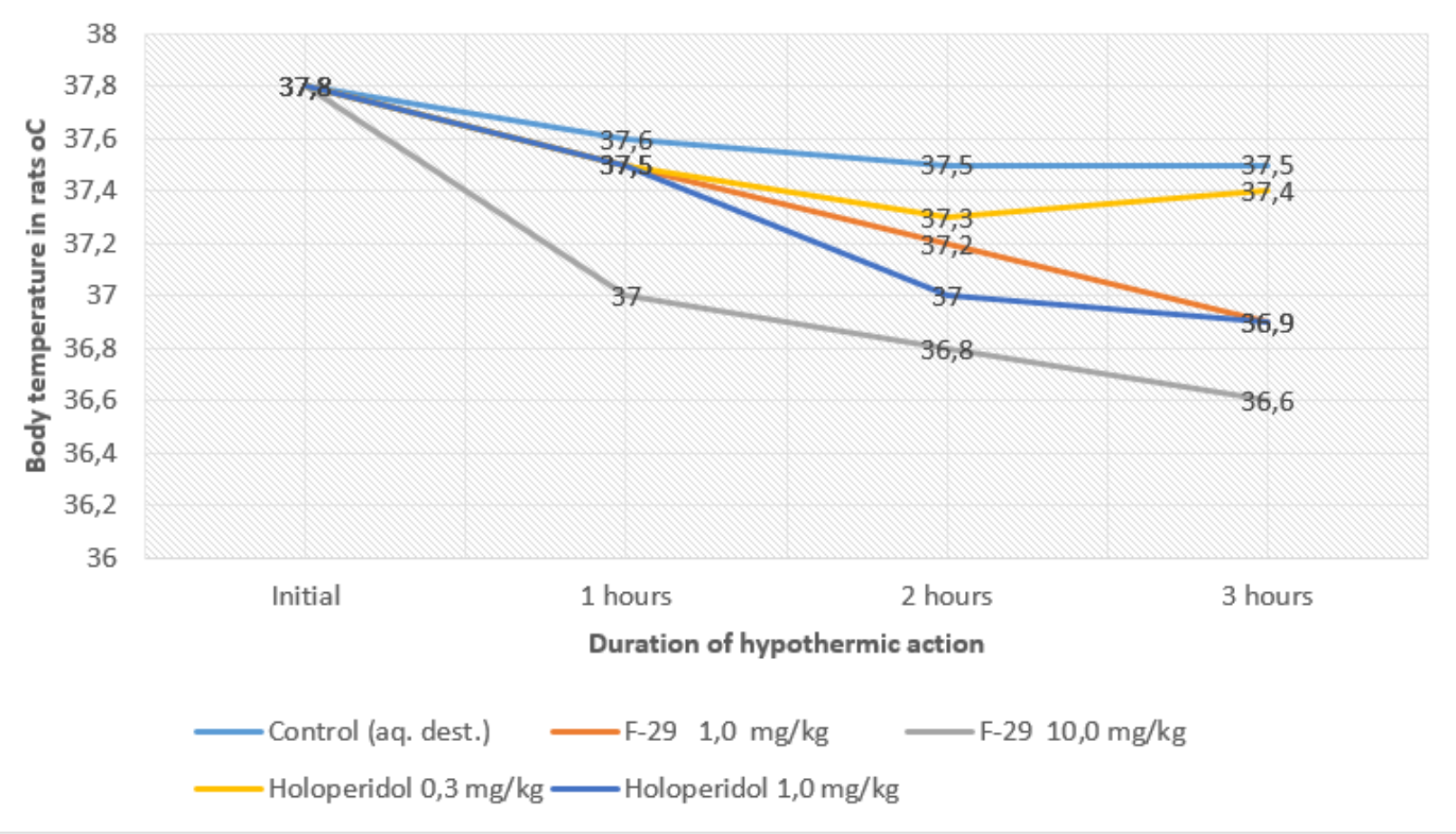

Fig. 5. Influence of F-29 and haloperidol on rat body temperature.

\section{Effect of F-29 and haloperidol on the locomotor action of phenamine.}

As you know, the psychopharmacological effects of phenamine are due to indirect stimulation of central $\alpha$-adrenergic and, to a lesser extent, dopamine receptors [6]. It was decided to study the effect of F-29 and haloperidol on the physiological effects of phenamine mediated by these receptors and to compare the nature of the action of F-29 and haloperidol.

\subsection{Experiments with F-29.}

In experiments on mice, $\mathrm{F}-29$ was administered in doses of $0.1 ; 1.0$ and $10 \mathrm{mg} / \mathrm{kg}$ orally and after 1 hour phenamine $6 \mathrm{mg} / \mathrm{kg}$ sc was administered. As the experiments showed, 2 and 3 hours after the administration of phenamine, an increase in motor activity was noted both in control mice and in experimental control group (see fig. 6). The data obtained indicate the absence of $a$ adrenergic blocking action of small doses of F29. 
The American Journal of Medical Sciences and Pharmaceutical Research (ISSN - 2689-1026)

Published: August 11, 2020 | Pages: 18-26

Doi: https://doi.org/10.37547/TAJMSPR/Volume02Issue08-03

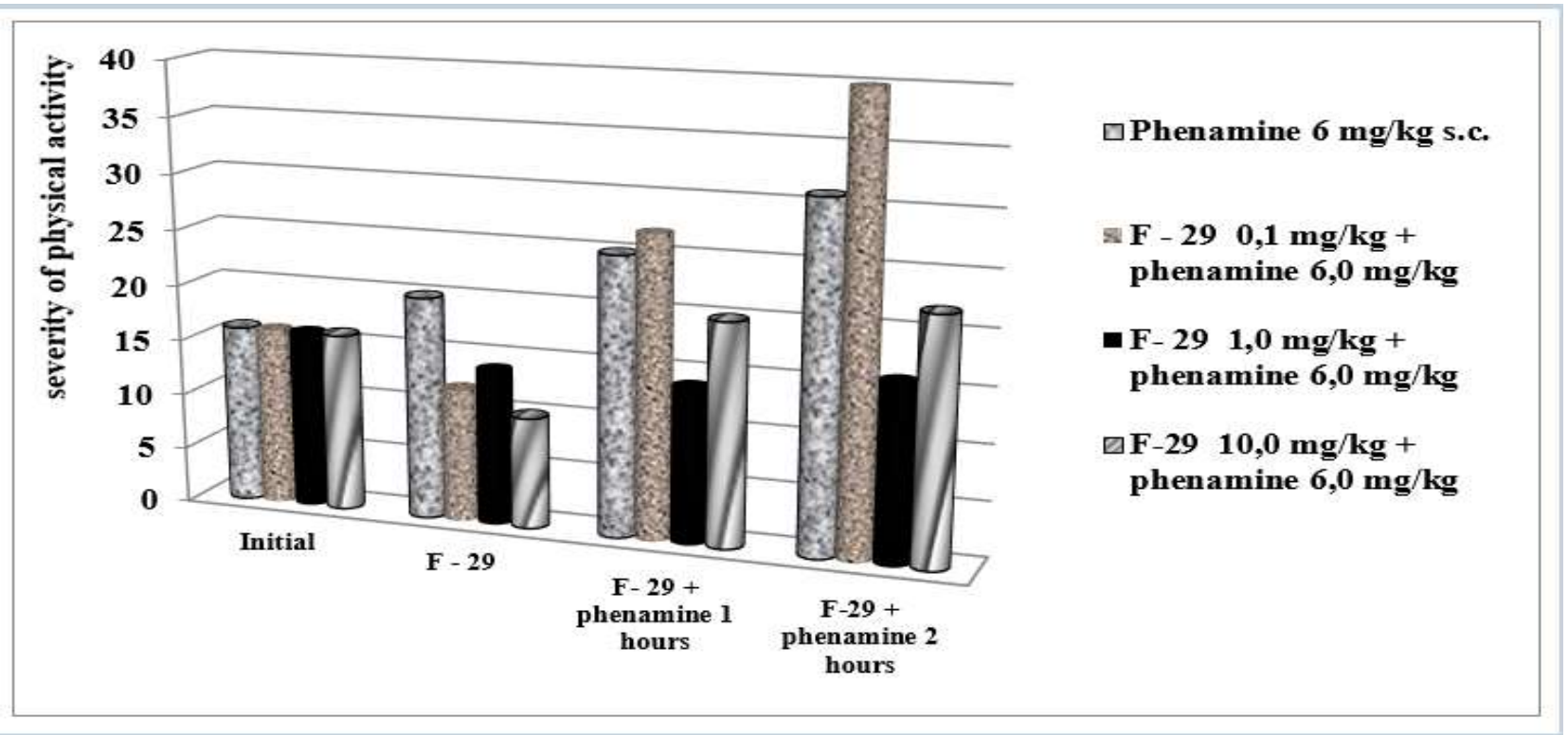

Fig. 6. Influence of F-29 on the locomotor action of phenamine.

\subsection{Effect of haloperidol on the locomotor action of phenamine.}

If in a previous experiment with F-29 it was established that an alkaloid in small "therapeutic" doses somewhat activates phenamine excitation of motor activity, then in experiments with haloperidol it was found that this neuroleptic, in contrast to F-29, in all experiments clearly inhibits the activating effect of phenamine (see fig. 7).

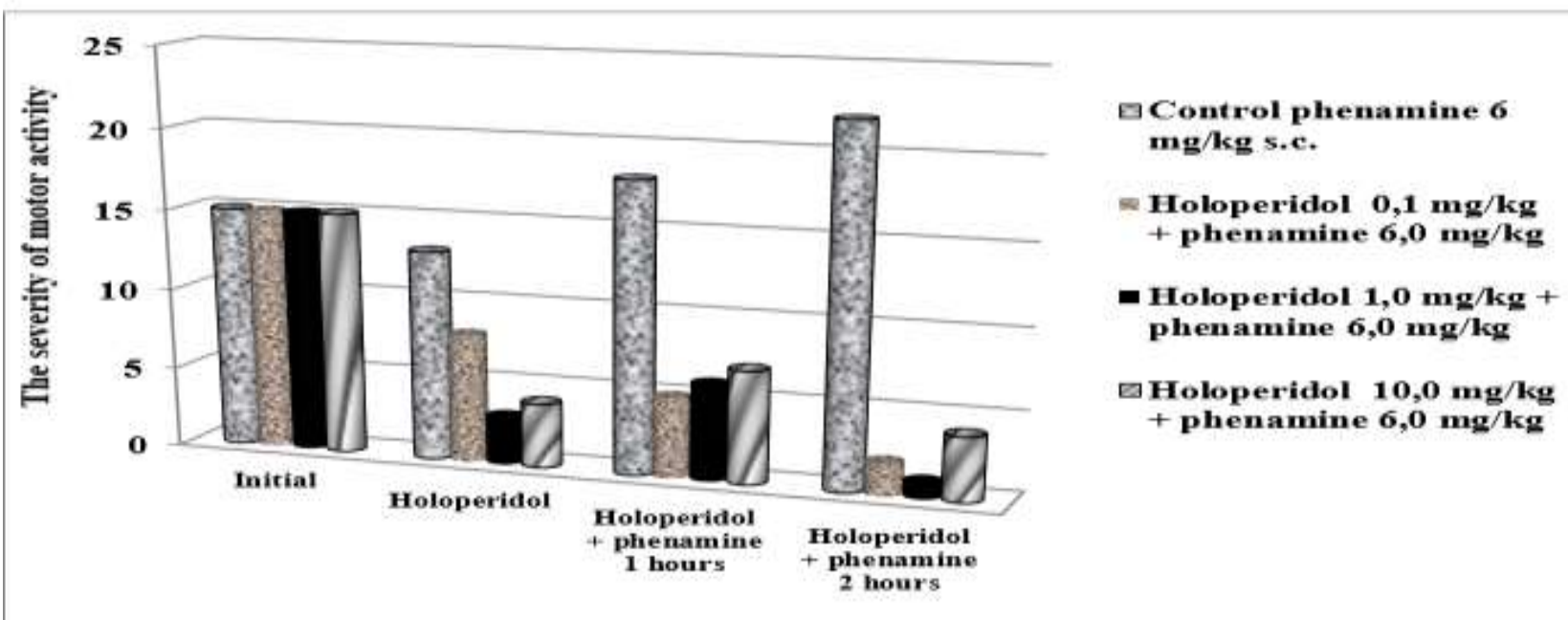

Fig. 7. Influence of haloperidol on the locomotor action of phenamine.

The revealed difference in the effects of F-29 and haloperidol in the test with phenamine can, to some extent, be explained by the literature data suggesting that the resorptive 
effect of phenamine is mainly due to its adrenostimulating effect and, to a lesser extent, due to the stimulation of dopamine receptors [6]. It follows from this that F-29 has a less pronounced adrenergic blocking effect than haloperidol. In haloperdol, adreno- and dopamine-blocking action is equally well expressed, and its antagonism to the action of phenamine in the experiments carried out is natural.

\section{Effect of F-29 on central M-cholinergic receptors.}

M-cholinergic receptors are widely involved in the regulation of the central nervous system. Classic antipsychotics, including haloperidol, block them. The blockade of central $M$ cholinergic receptors, on the one hand, has a positive therapeutic effect, and on the other, it is the cause of a large number of side effects that are noticeable in clinical use: visual disturbances, dry mouth, urinary retention, tachycardia, memory impairment, etc. [1]. The effect of F-29 on $M$ receptors was tested in the test for its effect on the duration of arecoline (10 mg / kg s/ c) tremor.

In the experiments carried out, it was found that F-29 in "therapeutic" doses of $0.1-1.0 \mathrm{mg}$ / kg shows some tendency to shorten the duration of tremor by $10-15 \%$ and only in the neuroleptic dose of $100 \mathrm{mg} / \mathrm{kg}$ shortened the tremor by $40 \%$ mice, i.e. showed some $M$ anticholinergic effect.

Thus, it can be assumed that in "therapeutic" doses F-29 does not have a noticeable $M$ anticholinergic blocking effect and is unlikely to cause the above vegetative disorders, which are characteristic of haloperidol [1].

\section{CONCLUSION}

F-29 can generally be taken as a neuroleptic. However, F-29 significantly differed from haloperidol in its effect on the phenamine locomotor action, where F-29 showed a tendency to potentiate this effect, while haloperidol strongly suppressed it in all experiments. This indicates that $\mathrm{F}-29$, in contrast to haloperidol at doses of 0.1 and 10.0 $\mathrm{mg} / \mathrm{kg}$, practically does not inhibit central adrenergic receptors. At therapeutic doses, F29 practically did not affect the central $M$ cholinergic receptors, while the M-cholinergic blocking effect of haloperidol is well known and is the cause of side effects [1]. The difference in doses causing pre- and postsynaptic D-blocking action in F-29 and haloperidol is significant, but it is leveled by 4.2 times less pronounced acute toxicity of F29. The presented differences between F-29 and haloperidol indicate that F-29 belongs to a new demanded class of atypical antipsychotics. F-29 has the potential to become one of the original atypical antipsychotics without some side effects of haloperidol, which is one of the "Dirty drugs" [8]. The distinctive properties of F-29, manifested in the absence of central adrenergic and M-anticholinergic blocking action, make the drug "cleaner" and, presumably, will cause certain advantages in clinical use. It is believed that atypical antipsychotics are in many cases more preferable than classical ones $[8,9,10]$.

\section{REFERENCES}

1. Mashkovsky M.D. / Neuroleptics. // Medicines (Reference). Sixteenth edition, Moscow, 2017, p. 52-88.

2. Berman B. / Neuroleptic Malignant Syndrome. // Neurohospitalist. 2011 Jan; 1(1): 41-47.

3. Gareri P. Segura-García C., Graziella V. et al. / Use of atypical antipsychotics in the elderly: a clinical review. // Clin. Interv. Aging. 2014; 9: 1363-1373. 
4. Zhurakulov Sh.N., Vinogradova V.I., Shakirov R.Sh. Synthesis of 1-aryltetrahydroisoquinoline alkaloids // Uzbek chemical journal. -Tashkent, -2014. -№ 1. -C. 13-16

5. Lapin I.P., Slepokurov M.V., / Anxiogenic activity of phenylethylamine in the test of social isolation in mice. // Pharmacol. and toxicol. 1991, v. 54, №. 6, p. 9-11.

6. Rothman R., Baumann M. , Dersch C. et al. / Amphetamine-type central nervous system stimulants release norepinephrine more potently than they release dopamine and serotonin. // Synapse. 2001 Jan;39(1):32-41.

7. Khabriev R.U. (Ed.). Methodological guide for experimental (preclinical) study of new pharmacological substances. M. 2005.

8. Beaumont G. / Antipsychotics - The Future of Schizophrenia Treatment. // Curr Med Res Opin. 2000;16(1).

9. Hershenberg R, Gros DF, Brawman-Mintzer O./ Role of atypical antipsychotics in the treatment of generalized anxiety disorder. // CNS Drugs. 2014 Jun;28(6):519-33.

10. Meltzer H. /What's atypical about atypical antipsychotic drugs? // Curr Opin Pharmacol. 2004 Feb;4(1):53-57. 